\title{
DWA water quality model - an instrument to support water management planning functions with the example of the Erft river
}

\author{
E. Christoffels \\ Erftverband, Bergheim, Germany
}

\begin{abstract}
The DWA water quality model can be used for a wide range of water management planning activities. Fields of application extend from data and system analysis, to the analysis of alternatives in water pollution control planning, to the implementation of alarm plans. The example of the Erft river is used to present the results of water quality simulations with a view to assessing current conditions and forecasting the future development of water quality.

Keywords: Erft, water quality model, plausibility check, water temperature, oxygen, ammonium, sumpwater, combined sewer overflow, riparian vegetation.
\end{abstract}

\section{Introduction}

In the course of progressive improvement of surface water quality, point sources are losing their significance as the dominant influence. Today water quality is affected to a high degree by many other important factors. Apart from external impacts, effects of internal processes within the water body are receiving greater attention than in the past. Predicting the impact of various water uses and the effects of measures to improve water quality is challenging because of the large number of relevant factors within a complex system. Despite this complexity, practical instruments are needed to predict the impact of human activities, to clearly demonstrate the need for measures based on existing water quality standards, and to foresee the outcome of such measures.

The DWA water quality model is an efficient instrument to support water management planning functions. It serves as a simulation model for creeks, brooks and rivers which is available as a software tool. This paper introduces the DWA water quality model using the example of the Erft river. 


\section{Structure of the DWA water quality model}

With the integrated water flow module as the basis, calculations within 17 other modules are possible (table 1). The modular structure allows the user to design the simulation at first as a simple model concept employing only a few modules. The concept can then be successively enlarged by adding further modules to simulate a complex application (Müller [1]).

Table 1: Modules of the DWA water quality model ATV-DVWKArbeitsgruppe GB-4.2 [2].

\begin{tabular}{|c|l|}
\hline Nr. & Name \\
\hline 0 & Water flow \\
\hline 1 & Solar radiation \\
\hline 2 & Water temperature \\
\hline 3 & Conservative substances, tracer \\
\hline 4 & BOD/COD \\
\hline 5 & Phosphorous \\
\hline 6 & Nitrogen compounds \\
\hline 7 & Silicate \\
\hline 8 & Diatoms \\
\hline 9 & Green algae \\
\hline 10 & Zooplankton I \\
\hline 11 & Zooplankton II \\
\hline 12 & Benthic flora and fauna, exchange with the sediment \\
\hline 13 & Suspended solids \\
\hline 14 & Oxygen balance \\
\hline 15 & pH-value \\
\hline 16 & Heavy metals \\
\hline 17 & Organic micro-pollutants \\
\hline
\end{tabular}

The water flow simulation module enables calculation of steady and unsteady flow for simple and branched river systems. The module is based on the complete St Venant Equation. To solve the transport equation, the method of characteristics is adopted. The algorithm used to solve the equation is nearly free of numerical dispersion. This method is particularly appropriate for describing dynamic processes. Thus, the procedure is highly suitable for simulation of accidental pollution events. Solar radiation is simulated taking into account all influences, from the upper part of the atmosphere to the water surface, and further down to the bottom of the water body. Solar radiation is the basis for simulation of temperature in the water body and on the bed, as well as for 
simulations of photosynthesis and photolysis. The conservative substances are only influenced by transport and dispersion. They are used mainly to verify the reproducibility of tracer experiments and thereby for adjusting of hydraulic parameters. The BOD is simulated together with the COD. Both are closely connected with several other modules; their decay influences oxygen concentration, in particular. In the next three modules nutrients (phosphorous, nitrogen and silicate) are simulated. These substances primarily influence plant growth; the nitrogen cycle additionally plays an important role in the fluctuation of the oxygen balance. Modules 8 to 12 describe the development of flora and fauna represented by phytoplankton, sessile macrophytes and phytobenthon as well as primary and secondary consumers, for instance macrozoobenthos. These modules are highly connected among themselves and with others. The suspended solids in the next module influence light conditions in the water body. They also affect the adsorption of substances as particulate matter, e.g. of heavy metals. The oxygen balance is essential for aerobic aquatic life and therefore one of the key elements of the model. The simulation of $\mathbf{p H}$-value is required because heavy metals are taken into account by the model and because, among other things, $\mathrm{pH}$ governs the equilibrium of ammonium and ammonia. Heavy metals and organic micro-pollutants are the last modules. In the heavy metal module the adsorption of seven heavy metals in the solid phase as a function of the respective solids concentration and prevailing $\mathrm{pH}$ value is considered. To simulate the fate of various organic micro-pollutants in the water body the model employs six different processes (photolysis, volatilisation, hydrolysis, biological decay, sorption/desorption, sedimentation). The specific properties of a simulated substance determine which of these processes is utilised.

The modules are highly interrelated. For each simulation problem a suitable combination has to be composed. To avoid mistakes due to incorrect module selection, a number of combinations for common applications have been predefined. Additionally, a large number of options are available to provide proper adjustment of the structure to the actual problem. For greater flexibility, the user can also select or switch off certain further functions according to their relevance in the case at hand.

\section{Erft river catchment}

The Erft river is situated in the western part of North Rhine-Westphalia, Germany. Flow direction is from south to north over a $110 \mathrm{~km}$ course (figure 1). The source is found in the Eifel hills region $30 \mathrm{~km}$ southwest of the former German capital, Bonn. Near the city of Euskirchen the river, with an average 1\% slope of decline, leaves the Eifel. In the middle and lower reaches the Erft descends at a very gradual slope of $0.1 \%$ to its confluence with the Rhine river near the city of Düsseldorf. 


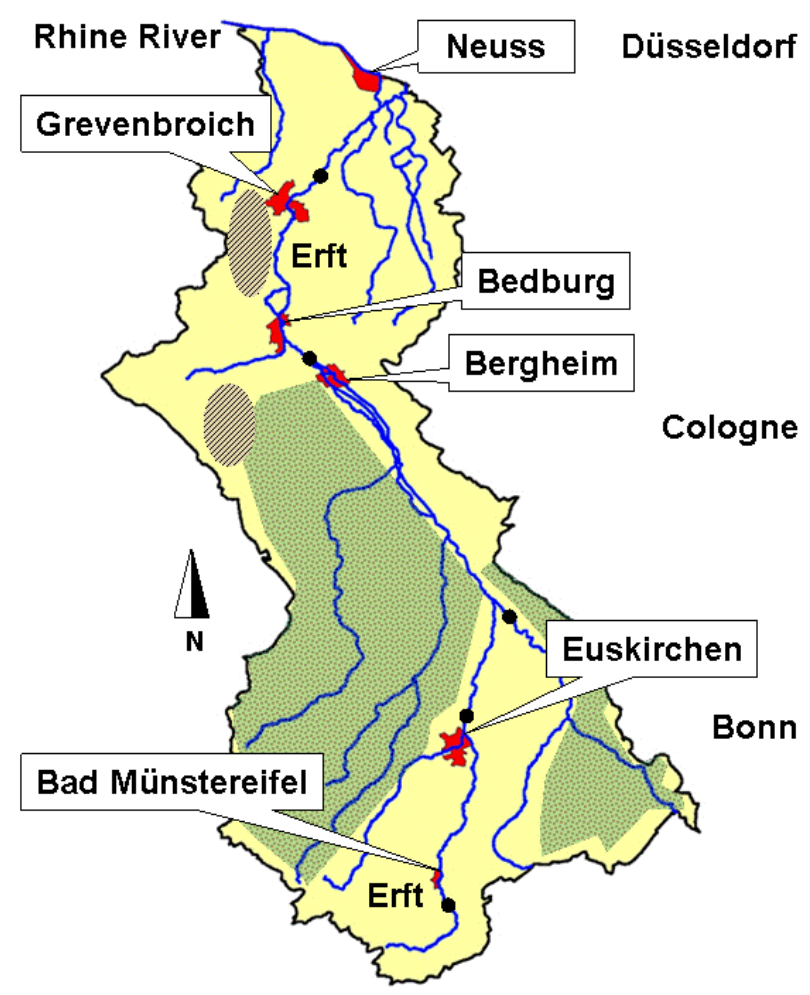

Figure 1: $\quad$ Erft River Basin (dotted = cultivation of field crops, hatched $=$ open pit lignite mines, black dots $=$ water quality monitoring stations).

Wide areas of the $1,800 \mathrm{~km}^{2}$ catchment are dominated by cultivation of field crops including wheat, rye, barley and sugar beets. Other significant activities impacting the river include:

- Discharge from wastewater treatment plants, from combined sewer overflows and storm-water retention tanks in case of intense rainfall;

- Gathering of water for aquatic biotopes, for power plants as heat exchange water and for irrigation of agricultural crops; and

- Recreation (e.g. sportfishing, boating).

In addition, the region is well known for its open pit lignite mines. Large quantities of groundwater must be pumped out to keep the pits dry. About 250 million cubic meters per year of this groundwater are discharged in the middle reach of the Erft. This discharged groundwater determines the flow rate in the middle and lower segments. The mean runoff at its mouth is around twelve cubic meters per second, of which the natural run off amounts to only about three cubic meters per second. 


\section{Erft water quality model}

The river-specific geo-elements relevant for establishing the Erft water quality model are (figure 2):

- Longitudinal profile of the watercourse

- Cross section profiles

- Weirs

- River reaches with lateral in- and outflow

- River reaches specific to riparian vegetation

- Municipal wastewater treatment plants

- Direct discharges

- Combined sewer overflows

- Storm water discharges

- Climate zones.

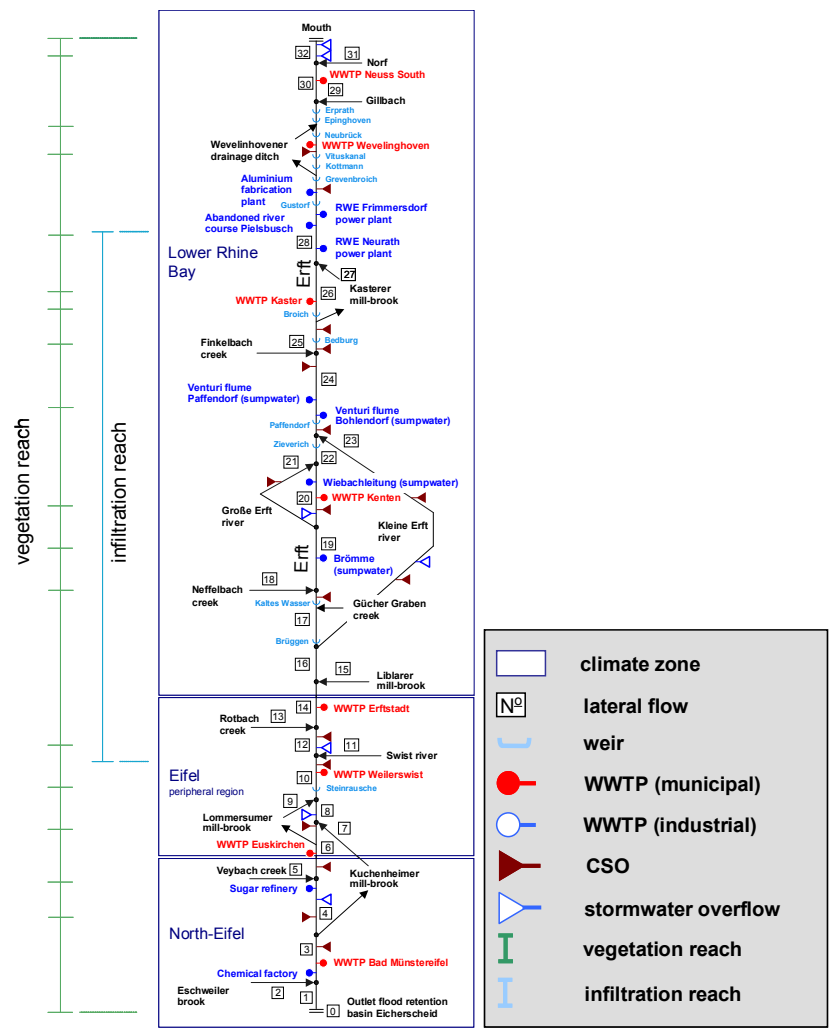

Figure 2: $\quad$ Erft river system - schematic diagram of relevant geo-elements for establishing the Erft water quality model. 
The watershed of the Erft is represented as three climate zones: a) North-Eifel (hills); b) Eifel peripheral (transition); and c) Lower Rhine Bay (lowland). The corresponding data (air temperature, wind velocity, etc.) is taken from data gathered by meteorological stations operated by the Erftverband, the water management association responsible for the catchment (and certain other areas). Main tributaries of the Erft are implemented in the model with all relevant geoelements; others are represented in a simplified manner as point discharges.

Lateral inflows from runoff (surface runoff, interflow) are treated as river section-specific. Sections are defined along the length of the river and its main tributaries. For convenience, the sections are delineated as either a) stretches between two tributaries or b) points such as the Erft headwater and confluences of main tributaries. Volumes of discharge for these drainage components are calculated by means of the NASIM $^{\mathcal{O}}$ precipitation-runoff simulation. Substance concentrations are considered on the basis of monitoring data.

Groundwater flow is calculated based on recorded river runoff data under dry weather conditions less the measured volume of corresponding WWTP discharge while taking into account the sumpwater influence. During dry weather other pathways do not deliver a relevant amount of water. To obtain usable data specifying the influence of groundwater flow on substance concentrations, a monitoring program has been established. This program is restricted to the upper catchment and is conducted in extended periods of zero precipitation, as occurred in 2005 for example. Such periods offer the best opportunity to separately study the influence of groundwater flow on substance concentrations in waters of the Erft catchment.

Lateral infiltration to the groundwater aquifer is observed in the region of brown coal mining activity. To consider this loss of river runoff due to the open pit mine, an infiltration reach is included in the model.

Discharges from municipal sewage treatment plants and direct discharges from industry are accounted for in the model. The relevant quantitative and qualitative parameters were determined from monitoring programs (operator self-checks, government surveillance) and water rights permits. Discharges from combined sewer systems and storm sewers can also be simulated, since a method required for determining overflow volume during discharge events for each individual structure is available (Christoffels [3]). The relevant substance concentrations stem from results obtained in an event-specific monitoring campaign to determine the dynamic fluctuation of rainfall-induced discharges from combined sewer systems and storm sewers.

To calculate radiation transmission within the water body (water temperature, algal growth) information about shading by riparian vegetation, structures and horizon elevations is necessary. For this purpose, the Erft watercourse is divided into so-called vegetation reaches (shading-segments). The classification is chosen so that within each shading-segment the degree of shielding from sunlight is largely uniform. Riparian vegetation alongside the watercourse, structures and horizon elevation have been identified by means of cartographic aerial photography (Land Survey Office North-Rhine-Westphalia), satellite images (Google Maps), digital elevation model (DEM) and available laser scan data. 


\section{Plausibility check}

In the Erft basin five water quality monitoring stations provide continuous recording of surface water contents (figure 1). In addition, the water level is recorded by several depth gauges placed along the Erft and its tributaries. With this collected data, an optimal plausibility check of water quality simulation results is possible.

Verification of model calculation plausibility is performed by running the model for selected periods in the past which feature desired scenarios such as dry weather, steady rain area-wide, extreme precipitation, etc. and comparing the modelling results with actual measurement data for the same periods. A time step of 1 hour (different time steps are arbitrary) is usually selected when applying the DWA water quality model. Calculation results are thus available at one hour intervals for the chosen scenarios in the past. Thanks to continuous real time measuring in water quality monitoring stations, measurement data are on hand for every time step of model application. Therefore, monitoring data and equivalent modelling results corresponding to any given time of day are usable for plausibility checks. Especially for small and medium-sized rivers with highly dynamic physicochemical conditions depending on time of day, the plausibility check of calculation results is only possible when synchronous data from monitoring and modelling are used.

In the example of water temperature (figure 3), good accordance between measurement data and results calculated using the model for absolute temperature level as well as diurnal fluctuation has been documented. This outcome is significant because nearly all water related processes depend on water temperature.

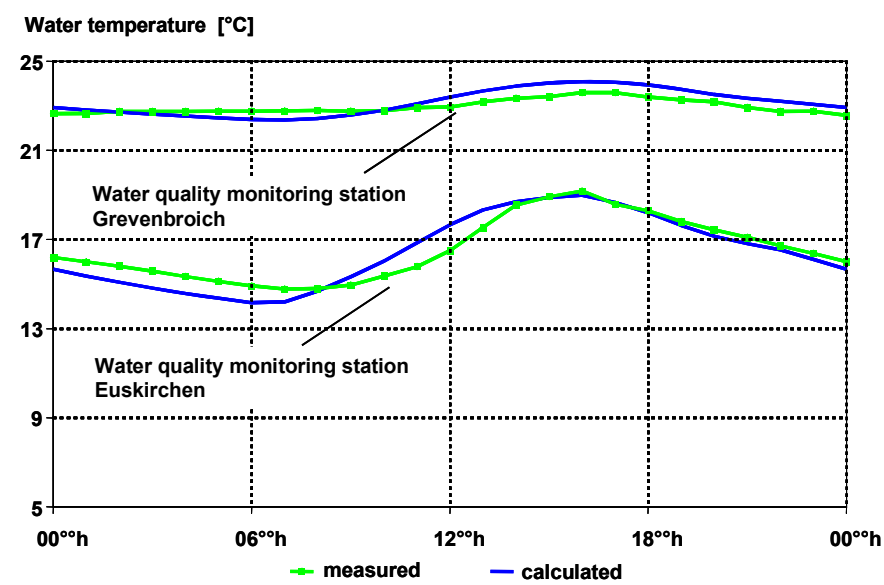

Figure 3: Measurement data and simulation results for water temperature in the Erft river, Euskirchen (upper reaches), Grevenbroich (lower reaches), 14 August 1997. 
Note: The large difference in water temperature between upper and lower reaches is explained by the discharge of warm sumpwater in the Erft middle reaches in connection with open cast brown coal mining (see also section 6.2.1).

Comparisons between measured water temperature data and simulation results are of interest, but it turns out that water temperature is not the best parameter of choice for performing valid plausibility checks, as explained below. It is worth noting, however, that the following processes which influence water temperature are taken into account in the DWA water quality model: heat exchange on the water surface; mixing of discharges of varying temperature from both point and non-point sources with the river water; and exchange with adjacent soil, which is especially important in smaller streams of low depth.

Despite these temperature related dependencies, the model component which exhibits dependency with the largest number of other parameters in the DWA water quality model is undoubtedly oxygen, not water temperature. Included in the oxygen module of the model are the following processes:

- physical oxygen input and outgassing (discharges, tributaries, water surface, weirs, turbines)

- photosynthesis, photorespiration

- decay of organic carbon compounds

- nitrification, denitrification

- respiration of periphyton, macrophytes and consumers.

As the oxygen module has the greatest number of interactions with other model components, a high number of the model's calculated processes involve determination of oxygen content. Thus, for plausibility checks oxygen is the parameter which delivers valid information as to whether or not the model results are acceptable.

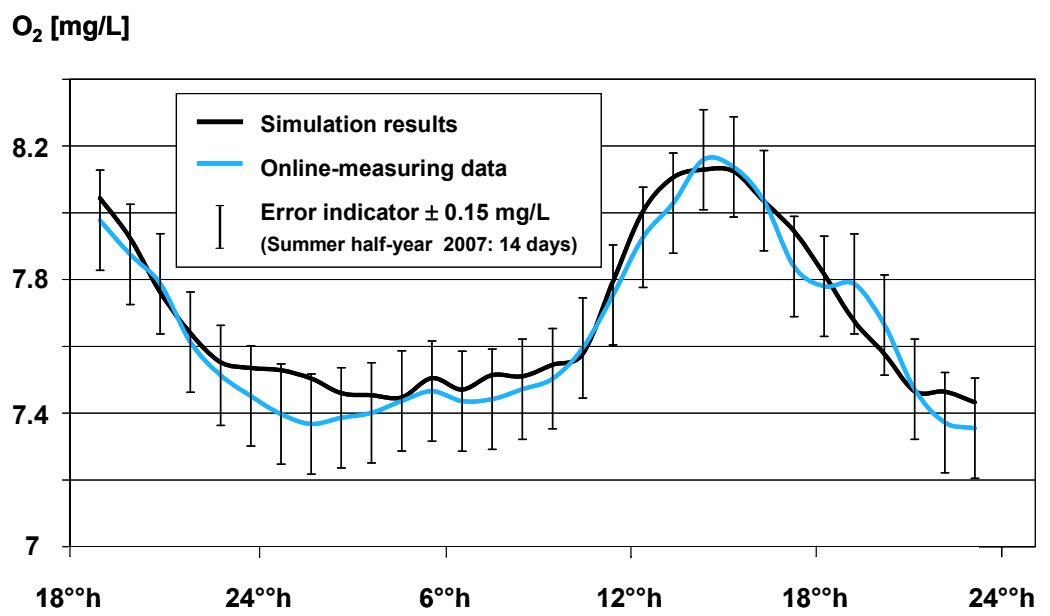

Figure 4: Measurement data and simulation results for oxygen content in the Erft river, Bergheim (middle reaches), 1 / 2 Sept. 2007. 
In figure 4 measurement data and results of model calculations for a summer day, with the example of oxygen content, are shown. As a criterium of acceptability, an error indicator for the oxygen parameter has been introduced. If the model results are within $+/-0.15 \mathrm{mg} / \mathrm{L}$ of the measurement results, the model calculation is assumed acceptable. This comparison is carried out automatically by the software program, which also delivers information on how many days in the chosen period (here: summer 2007) a measured diurnal course similar to the modelled one, within the $+/-0.15 \mathrm{mg} / \mathrm{L}$ range, has actually occurred (here: 14 days). So, this curve of daily oxygen fluctuation used for the plausibility check occurs relatively often during the summer season.

\section{Results obtained using the water quality model}

The model has proven to be an effective way of obtaining useful information on present and future Erft river water quality under various circumstances. Some examples are provided in this section.

\subsection{Simulation of water quality status quo}

Simulation of present water quality conditions, supported by measurement data, provides an increase in knowledge: Results can be obtained for any point the user chooses along the water course, which is not feasible in the framework of monitoring program for reasons of cost. Furthermore, simulation results provide information on water quality for time intervals which are not usually covered by monitoring programs commonly in use, for instance at night. Examples are given below for water temperature, oxygen and ammonium.

\subsubsection{Water temperature}

Results of water quality simulation of present conditions show that the Erft upper reaches have, as is typical for reaches with a small runoff, clear diurnal fluctuations in water temperature (figure 5). The dominant influence on water temperature in this part of the Erft is air temperature. In summer months the significant diurnal fluctuations in the upper reaches are clearly attenuated by cold water inflow from Veybach creek, an Erft tributary ( $\mathrm{km} \mathrm{76.5).} \mathrm{The} \mathrm{Veybach}$ receives a groundwater discharge of about $300 \mathrm{~L} / \mathrm{s}$ at a nearly constant $10^{\circ} \mathrm{C}$. This cold water is drainage from a former ore mine.

In the middle and lower reaches water temperature is influenced by discharges of warm groundwater $(\mathrm{km} \mathrm{40)}$ pumped out to keep the open pit lignite mines dry (see section 3 above). This water is of a constant high temperature with little fluctuation $\left(24.5^{\circ} \mathrm{C} \pm 0.5^{\circ} \mathrm{C}\right)$.

The simulation shows that the warm water discharges raise the temperature to a constant high level in comparison with the reaches upstream. So, water temperature in the middle and lower reaches is subject to much less diurnal fluctuation than temperature near the source. 


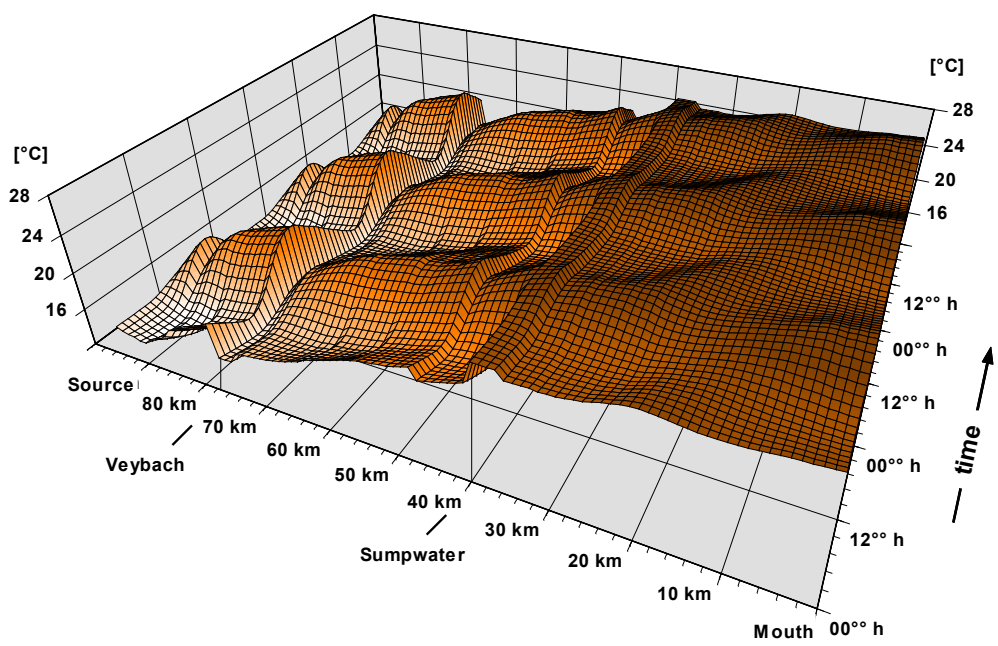

Figure 5: Water temperatures in the Erft, scenario: dry weather, summer 2006 - water quality simulation results.

\section{$\mathrm{O}_{2}[\mathrm{mg} / \mathrm{L}]$}

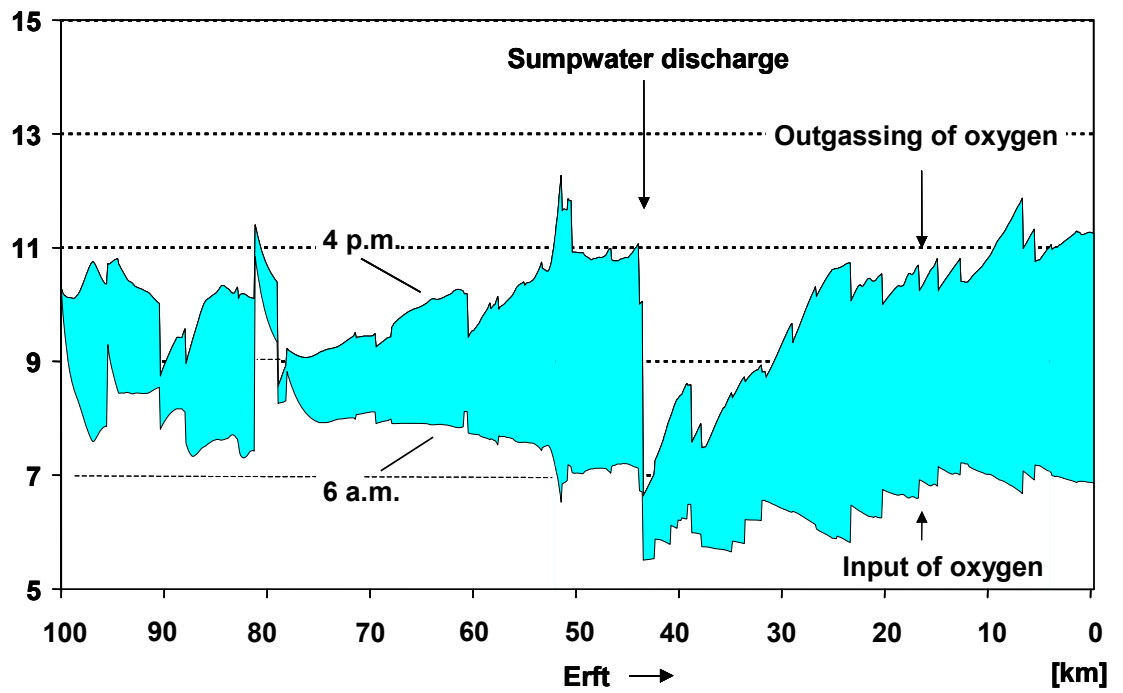

Figure 6: Oxygen concentrations in the Erft, scenario: dry weather, summer 2000 - water quality simulation results.

\subsubsection{Oxygen}

Because the groundwater pumped into the Erft in support of mining activity stems from great depths (up to $500 \mathrm{~m}$ ) it is not only warm, but poor in oxygen. 
Measures are thus taken to enrich the groundwater with atmospheric oxygen at the most significant discharge point. Nonetheless, simulation correctly predicts low oxygen concentration in the middle and lower reaches (figure 6). The summer months demand particular attention because of high water temperature and resultant low oxygen saturation capacity.

Beside such seasonal effects, the simulation of oxygen concentration shows significant diurnal fluctuation (minimum at 6 a.m. / maximum at 4 p.m.). During the day phytogenic input (photolysis) raises the oxygen concentration. At night concentration is reduced by respiration. In the lower reaches the water level is regulated by several weirs. Calculations made using the model show clear local effects on oxygen concentration stemming from weir overflows. At the time of day when oxygen concentration is at a minimum (6 a.m.), overflows from the weirs cause an input of oxygen. During oxygen oversaturation (4 p.m.), weir overflows cause an outgassing of oxygen.

\subsubsection{Combined sewer overflows}

The DWA water quality model makes it possible to calculate time-variant flows and concentrations. The model is thus suitable for describing effects in the water body stemming from unsteady discharges and dynamic concentration gradients of combined sewer overflows (CSO).

The quantity and quality of discharges from combined sewages in the Erft basin is identified by sewer modelling combined with event driven monitoring systems. A water quality simulation performed on the basis of an event of combined sewer overflows in the middle reaches demonstrates that such overflow can be the predominant factor influencing $\mathrm{NH}_{4}-\mathrm{N}$ concentration (figure 7). The figure shows the spatial and temporal resolution for calculated ammonium nitrogen content along the river's entire length for two days. The scenario presented is typical for summer: dry weather punctuated by sudden heavy rainfall. Nitrogen concentrations exceeding $0.15 \mathrm{mg} \mathrm{NH} \mathrm{NH}_{4} \mathrm{~N} / \mathrm{L}$ are highlighted progressively in darker shades. At concentrations above the $0.15 \mathrm{mg}$ $\mathrm{NH}_{4}-\mathrm{N} / \mathrm{L}$ threshold, fish and fish fry could be affected (Brandorff and Masch [4]).

The following observations concerning ammonium clearly demonstrate the correspondence of highly elevated ammonium concentration with entry of combined sewer overflow. The methodology permits detailed substance profiling along the entire length of the river.

In the upper reaches a small, localised increase in ammonium is detected. This is accounted for by the fact that a relatively high volume of discharge from the wastewater treatment plant $\left(0.2 \mathrm{~m}^{3} / \mathrm{s}\right.$ under dry weather conditions $)$ serving the city of Euskirchen enters the river in an area where the Erft flow volume is relatively low $\left(0.6 \mathrm{~m}^{3} / \mathrm{s}\right.$ minimum flow $)$. In the middle reach at kilometre 40 sumpwater is discharged which contains $0.39 \mathrm{mg} / \mathrm{L}$ ammonium nitrogen. This concentration probably stems from reduction processes in the tertiary aquifer (Großer Erftverband [5]).

Still with reference to figure 7 , as a result of precipitation in the $25-50 \mathrm{~km}$ stretch within the middle reaches, CSO No. 629 discharged with a first flush at a 
rate of $285 \mathrm{~L} / \mathrm{s}$ and $6 \mathrm{mg} \mathrm{NH}-\mathrm{N} / \mathrm{L}$. This release caused a stress focal point at $48.12 \mathrm{~km}$ with $1.4 \mathrm{mg} \mathrm{NH}_{4}-\mathrm{N} / \mathrm{L}$. Not far downstream, with the arrival of inflows of $340 \mathrm{~L} / \mathrm{s}$ in total with $<0.1 \mathrm{mg} \mathrm{NH} 4-\mathrm{N} / \mathrm{L}$ from the Neffelbach tributary and Brömme sumpwater, the high ammonium nitrogen concentrations quickly returned to baseline level.

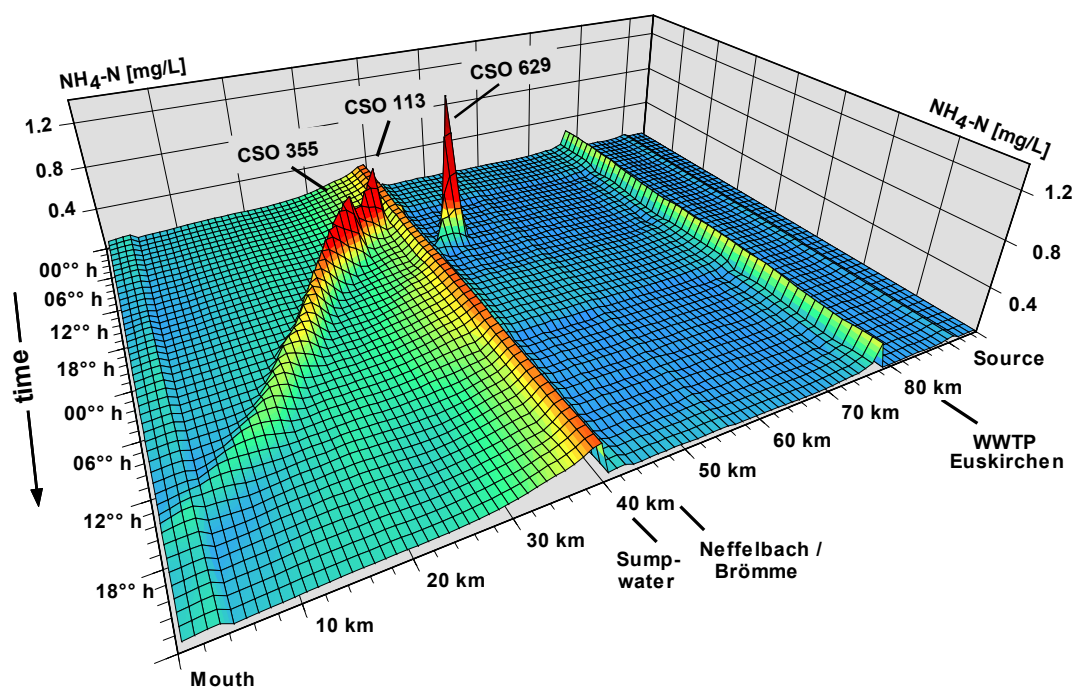

Figure 7: $\mathrm{NH}_{4}-\mathrm{N}$ concentrations in the Erft arising from combined sewer overflows - scenario: midsummer 2006 with rainfall event in the middle reaches (rainfall corridor $25 \mathrm{~km}-50 \mathrm{~km}$ : $14 \mathrm{~mm}$ in $2 \mathrm{hrs}$ ) water quality simulation results.

Ammonium contained in a discharge from a CSO at $41.23 \mathrm{~km}$ is not noticeable because of superimposing of sumpwater. Overflows from CSO No. $113\left(0.76 \mathrm{~m}^{3} / \mathrm{s}\right.$ maximum discharge $)$ and No. $355\left(0.67 \mathrm{~m}^{3} / \mathrm{s}\right.$ maximum discharge) account for elevated ammonium concentrations down to the lower reach at $10 \mathrm{~km}$. The speed with which the ammonium nitrogen cloud travels downstream is about $0.3 \mathrm{~m} / \mathrm{s}$.

\subsection{Simulating future conditions}

Water quality simulations are typically used in planning processes to help anticipate effects of projects under consideration in or along a water course. Taking a variety of planning alternatives, the modelled "status quo" of the real river system must be modified according to the conditions prognosticated under each scenario. The results of such modelling are then useful in evaluating planning alternatives. 


\subsubsection{Reducing groundwater discharges into the Erft}

Groundwater discharges from the open pit lignite mines are the predominant factor in determining nitrate concentrations in the middle and lower reaches. At present, concentrations are low due to dilution, since the discharged groundwater is nearly free of nitrate nitrogen. Figure 8 shows the significant attenuation of nitrate concentrations downstream from the groundwater inflow.

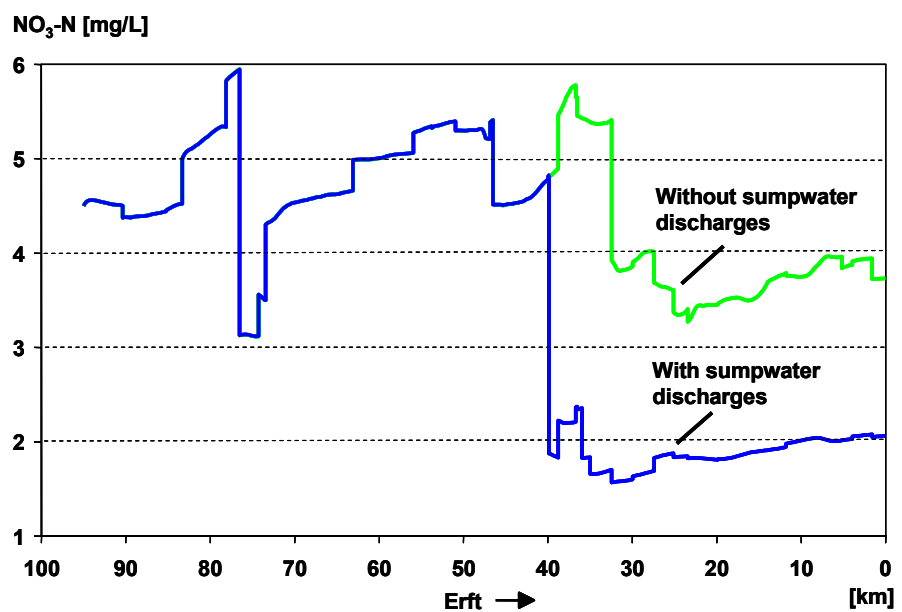

Figure 8: $\quad \mathrm{NO}_{3}-\mathrm{N}$ concentrations in the Erft with and without the influence of discharged groundwater, scenario: dry weather - water quality simulation results.

In view of the planned cessation of groundwater discharges in approximately 30 years, Erft water management planners need to make a reasonable estimate of future nitrate concentration levels.

The results of the water quality simulation show that under otherwise unmodified conditions concomitant with the elimination of water arising from the reduced groundwater discharges, nitrate concentrations rise to nearly double the level now observed in the middle and lower reaches (see figure 8 "with sumpwater" and "without sumpwater"). In these sections the diurnal fluctuation of $\mathrm{NO}_{3}-\mathrm{N}$ concentration will be more significantly influenced in the future by discharges from wastewater treatment plants because of the loss of dilution from the groundwater discharges.

\subsubsection{Attenuation of solar radiation due to vegetation}

In narrow rivers attenuation of solar radiation due to riparian vegetation is meaningful for photosynthesis, photolysis and the water temperature regime. Here the case of water temperature is of particular interest. In the Erft, effects of riparian vegetation will become more prominent after cessation of warm groundwater discharges. 
Figure 9 shows the results of a water quality simulation reflecting future absence of warm groundwater discharges under three scenarios: no vegetative cover, riparian vegetation as today (status quo) and completely closed riparian vegetation. If the present low vegetation level is sustained in the future, the effect on water temperature will be nearly the same as if there was no riparian vegetation at all. At the other extreme, the water quality simulation in a scenario of hypothetically complete vegetative cover gives an idea of the maximum possible influence of vegetation on the water temperature profile: Complete vegetative cover would substantially reduce water temperature along the entire length.

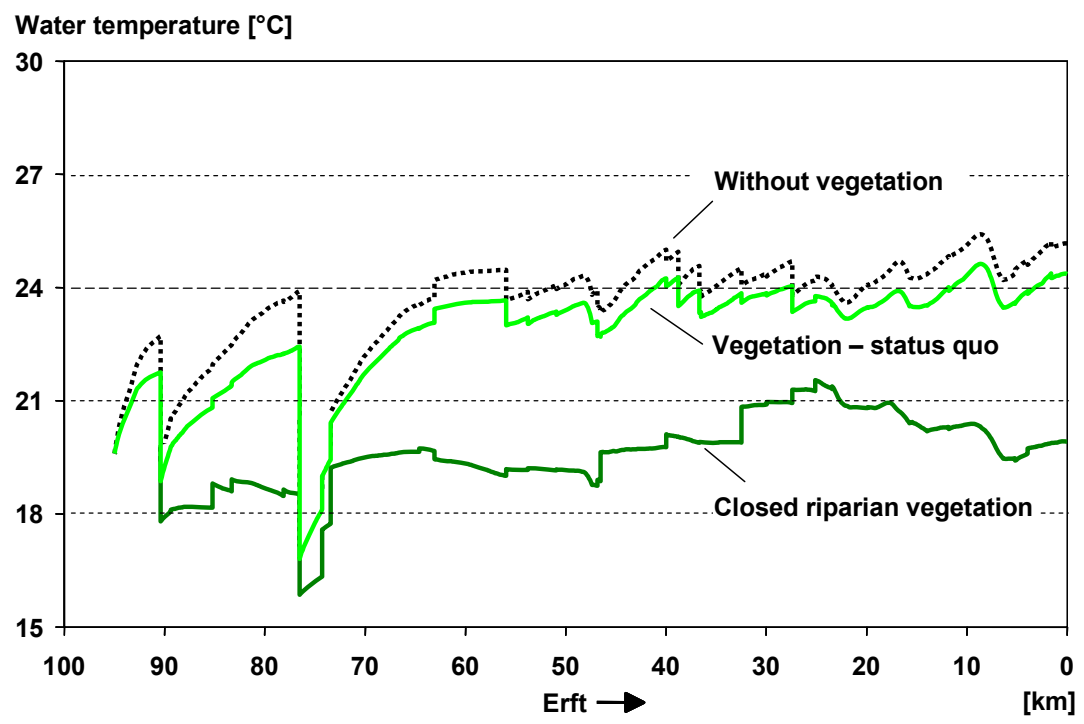

Figure 9: Dependence of Erft summer water temperatures on riparian vegetation, scenario: absent groundwater discharges - water quality simulation results.

\section{Conclusion}

The DWA water quality model permits evaluation of water quality driving forces in streams, brooks and rivers. Based on simulation of present water quality conditions, it is possible to simulate future conditions under various scenarios. Applying this model to the Erft basin, water management planners can make prognoses on water quality after cessation of groundwater discharges from the open pit lignite mines. With the model it is also possible to prognosticate the influence of wastewater treatment plants, combined sewer overflows, riparian vegetation, riverine substance cycles and other significant factors affecting water quality. 
The DWA model thus serves as a decision support system in planning water management activities. Thanks to its ease of application, the suitability of the model ranges from simple flowing water systems with single-factor questions to complex river networks featuring multiple loading conditions.

\section{Acknowledgement}

The modelling procedure presented was funded in the framework of the European Union initiative Life + , within which the $\mathrm{M}^{3}$-project "Application of integrated modelling and monitoring approaches for river basin management evaluation" has been established. The European Union is gratefully acknowledged for its support and funding initiatives.

\section{References}

[1] Müller St., Anwendung des ATV-Gewässergütemodells in der wasserwirtschaftlichen Praxis, 32. IWASA Internationales Symposium Aachen, Gewässergüte Mechanismen - Modelle - Methoden, Lehrstuhl und Institut für Wasserbau und Wasserwirtschaft, Rheinisch-Westfälische Technische Hochschule Aachen, Herausgeber: Univ.-Professor Dr.-Ing. Jürgen Köngeter, S. 277 ff. ISBN 3-86130-112-1, Verlag Mainz, 2008.

[2] ATV-DVWK-Arbeitsgruppe GB-4.2, Handbuch ATV-DVWK-Gewässergütemodell, Herausgeber: ATV-DVWK Hauptgeschäftsstelle Hennef, 2002.

[3] Christoffels E., Monitoring und Modellanwendung - Entwicklung eines Immissionsinventars am Beispiel der Erft, Hrsg. Erftverband, D-Bergheim, ISBN 978-3-00-024445-2, 2008.

[4] Brandorff G. O. and Masch J., Stickstoff in Oberflächengewässern, Freie Hansestadt Hamburg Umweltbehörde, http://fhh.hamburg.de/.../behoerden/stadtentwicklung_umwelt/umwelt/abwa sser/pdf/stickstoff,property=source.pdf, 2001.

[5] Großer Erftverband, Hydrogeologie und Grundwasserbeschaffenheit im Erftkreis - dargestellt an ausgewählten Parametern, Schenk, V., Wollny, R., Eigenverlag, June 1985. 